\title{
Anticancer effects of methanol extract of Myrmecodia platytyrea Becc. leaves against human hepatocellular carcinoma cells via inhibition of ERK and STAT3 signaling pathways
}

\author{
ANNA JU, YOUNG-CHANG CHO, BA REUM KIM, SEWOONG LEE, \\ HIEN THI THU LE, HUONG LAN VUONG and SAYEON CHO \\ Laboratory of Molecular and Pharmacological Cell Biology, College of Pharmacy, \\ Chung-Ang University, Seoul 06974, Republic of Korea
}

Received August 24, 2017; Accepted October 7, 2017

DOI: 10.3892/ijo.2017.4178

\begin{abstract}
Myrmecodia platytyrea Becc., a member of the Rubiaceae family, is found throughout Southeast Asia and has been traditionally used to treat cancer. However, there is limited pharmacological information on this plant. We investigated the anticancer effects of the methanol extract of Myrmecodia platytyrea Becc.leaves (MMPL) and determined the molecular mechanisms underlying the effects of MMPL on metastasis in human hepatocellular carcinoma (HCC) cells. MMPL dose-dependently inhibited cell migration and invasion in SK-Hep1 and Huh7 cells. In addition, MMPL strongly suppressed the enzymatic activity of matrix metalloproteinases (MMP-2 and MMP-9). Diminished telomerase activity by MMPL resulted in the suppression of both telomerase activity and telomerase-associated gene expression. The levels of urokinase-type plasminogen activator receptor (UPAR) expression as well as the phosphorylation levels of signal transducer and activator of transcription 3 (STAT3) and extracellular signal-regulated kinase (ERK) were also attenuated by MMPL. The above results collectively suggest that MMPL has anticancer effects in HCC and that MMPL can serve as an effective therapeutic agent for treating human liver cancer.
\end{abstract}

\section{Introduction}

Cancer is one of the greatest public health burdens worldwide, causing abnormal cell growth through DNA mutation

Correspondence to: Professor Sayeon Cho, Laboratory of Molecular and Pharmacological Cell Biology, College of Pharmacy, Chung-Ang University, 84 Heukseok-Ro, Dongjak-Gu, Seoul 06974, Republic of Korea

E-mail: sycho@cau.ac.kr

Key words: methanol extract of Myrmecodia platytyrea leaves, urokinase-type plasminogen activator receptor, extracellular signalrelated kinase, signal transducer and activator of transcription 3 that often leads to death (1). Metastatic tumors, in particular, result in $90 \%$ of human cancer deaths (2). Cancer metastasis contributes to both morbidity and mortality, and it is the most challenging target of effective cancer treatment (3). Metastatic cells detach from the primary tumor, travel to other sites through the circulatory or lymphatic system, and adhere and proliferate in distant organs, resulting in highly incurable and fatal diseases $(3,4)$. Recent research has focused on understanding the precise mechanism of metastasis in order to prevent various steps in the process (5).

In addition, there is emerging evidence that telomerase is a promising target for the development of new cancer therapies $(6,7)$. Elevated telomerase activity has been found in approximately $90 \%$ of cancer cells (8). Cancer cells can be immortalized by maintaining the telomere length, which is regulated by telomerase. Reactivation or increased expression of telomerase leads to continuous proliferation of cancer cells (9).

Natural products have been used in human medicine since ancient times. For several decades, plants and plant-derived compounds have been used to combat cancer often with fewer side effects than traditional treatments (10). Since plants have been a useful source of approved anticancer agents, many efforts have been undertaken to investigate the wide range of pharmacological effects of plants against various types of cancer $(11,12)$.

Myrmecodia (Rubiaceae) is a genus of the epiphytic myrmecophytes or ant-plant, which is locally known as Sarang Semut. This genus is native to Southeast Asia, but it can also be found in Myanmar, Indochina, and northern Queensland in Australia (13). Myrmecodia plants contain a highly specialized tuber and modified stems, which are used by ant colonies (14). Myrmecodia species have traditionally been used to treat diseases such as ulcers, tumors, cancer, hepatitis, and coronary artery disease (15).

In pharmacological studies, Myrmecodia pendens and tuberose are both considered to be potential anticancer agents. Water extracts of Myrmecodia pendens have been shown to inhibit HeLa and MCM-B2 cancer cell growth (16). Five flavonoids of Myrmecodia pendens, kaempferol, luteolin, rutin, quercetin, and apigenin, were identified and quantified, and 
some or all of these phenolic compounds may have anticancer properties (17). Ethanol extracts of Myrmecodia tuberose have been shown to suppress tumor growth and induce apoptosis of oral carcinoma cells (18). In addition, this plant extract significantly increased macrophage phagocytosis and lymphocyte proliferation in doxorubicin-induced immunosuppressed rats (19). Since one of the main side effects of doxorubicin in cancer chemotherapy is immunosuppression, this research supports the notion that Myrmecodia tuberose could be used as a complementary agent for cancer treatment by improving immune responses $(20,21)$.

Although Myrmecodia platytyrea Becc. is commonly used for cancer treatment by local residents throughout Southeast Asia, there has been little scientific investigation about its pharmacological activity. Bioactive compounds such as stigmasterol, morindolide, and flavonoids have been found in the tuber of the plant (22). The tuber extract has demonstrated toxic effects on HepG2 cells without affecting normal monkey kidney cells, suggesting this extract inhibits the growth of human hepatocellular carcinoma (HCC) (23). However, very little is known about the biological activity of Myrmecodia platytyrea Becc. leaves. This study investigated the potential anticancer activity of the methanol extract of Myrmecodia platytyrea Becc. leaves (MMPL) in HCC cells and the mechanism underlying these effects.

\section{Materials and methods}

MMPL preparation. The methanol extract of Myrmecodia platytyrea Becc. leaves (Voucher no. KRIBB0047070) was purchased from the International Biological Material Research Center in Korea Research Institute of Bioscience and Biotechnology (KRIBB, http://www.ibmrc.re.kr, Daejeon, Korea). A voucher specimen (KRIBB0047070) was deposited at KRIBB. The extract was diluted in dimethyl sulfoxide (DMSO; Sigma-Aldrich, St. Louis, MO, USA) and added directly to the culture media. To avoid cell damage, the final concentration of DMSO never exceeded $1 \%$.

Cell culture and reagents. Human hepatoma cell lines with different metastatic potentials, including SK-Hep1 with high metastatic potential and Huh7 with low metastatic potential (Korean Cell Line Bank, Seoul, Korea), were maintained in Dulbecco's modified Eagle's medium (DMEM) or Roswell Park Memorial Institute 1640 (RPMI-1640) supplemented with $10 \%$ fetal bovine serum (FBS), $50 \mathrm{U} / \mathrm{ml}$ penicillin and $50 \mu \mathrm{g} / \mathrm{ml}$ streptomycin (Gibco-BRL, Grand Island, NY, USA) at $37^{\circ} \mathrm{C}$ in a humidified $5 \% \mathrm{CO}_{2}$ atmosphere.

Rabbit polyclonal anti-signal transducer and activator of transcription 3 (STAT3, cat no. sc-482), rabbit polyclonal anti-Akt (cat no. sc-8312), rabbit polyclonal anti-phospho (p)-Akt (Ser473, cat no. sc-7985), mouse monoclonal antic-Jun N-terminal kinase (JNK, cat no. sc-7345), rabbit polyclonal anti-inhibitor of $\kappa \mathrm{B} \alpha(\mathrm{I} \kappa \mathrm{B} \alpha$, cat no. sc-371), and mouse monoclonal anti- $\alpha$-tubulin (cat no. sc-8035) antibodies were obtained from Santa Cruz Biotechnology, Inc. (Santa Cruz, CA, USA). Rabbit polyclonal anti-uPAR (cat no. 9692), rabbit polyclonal anti-p-STAT3 (Tyr705, cat no. 9131), rabbit polyclonal anti-p-p38 (Thr180/Tyr182, cat no. 9211), rabbit polyclonal anti-p38 (cat no. 9212), rabbit polyclonal anti-extrcellular signal-regulated kinase (ERK, cat no. 9102), mouse monoclonal anti-p-ERK (Thr202/Tyr204, cat no. 9106), and rabbit polyclonal anti-p-JNK (Thr183/Tyr185, cat no. 9251) were purchased from Cell Signaling Technology Inc. (Danvers, MA, USA). 5-Fluorouracil (5-FU) was from Sigma-Aldrich and BIBR1532 was from ApexBio Technology (Houston, TX, USA). Emodin was purchased from Tokyo Chemical Industry Co., Ltd. (Tokyo, Japan).

Cell viability assay. Cells were seeded in 24-well plates $\left(1-1.5 \times 10^{5}\right.$ cells/well) and treated with various concentrations of MMPL for either $24 \mathrm{~h}$ or $48 \mathrm{~h}$ with media containing $1 \%$ or $10 \%$ FBS. Cell viability was evaluated using EZ-Cytox solution (Daeil Lab, Seoul, Korea) according to the manufacturer's instructions. Briefly, EZ-Cytox solution was added to each well and the plate was incubated for $1 \mathrm{~h}$ at $37^{\circ} \mathrm{C}$. The optical density (OD) of the supernatants was measured at $450 \mathrm{~nm}$ using a Synergy H1 Microplate Reader (BioTek Instruments, Winooski, VT, USA).

Wound healing assay. SK-Hep1 and Huh7 cells were seeded in 6-well plates $\left(0.5-1 \times 10^{6}\right.$ cells/well) and cultured until they reached $90 \%$ confluence. The wound area was created using a scratcher tip (0.5 mm; SPL Life Sciences, Gyeonggi-do, Korea). The detached cells were removed with phosphate-buffered saline (PBS) supplemented with media containing 1\% FBS and treated with the indicated concentration of MMPL for $24 \mathrm{~h}$. The cells that migrated into the wound surface were observed using a JuLI Stage Real-Time Cell History Recorder (NanoEnTek Inc., Seoul, Korea). The change in wound closure is represented as the percent of wound recovery. All experiments were performed in triplicate.

Transwell invasion and migration assay. SK-Hep1 cells ( $5 \times 10^{4}$ cells/well) in $250 \mu 1$ of media containing $1 \%$ FBS were added to the upper chamber with or without MMPL, and the lower chamber was filled with $500 \mu \mathrm{l}$ of media containing $10 \%$ FBS. The plates were incubated at $37^{\circ} \mathrm{C}$ and $5 \% \mathrm{CO}_{2}$ for $18 \mathrm{~h}$. For the Matrigel invasion assay, 24-Transwell plates (pore size, $8 \mu \mathrm{m}$ ) were coated with $30 \mu \mathrm{l}$ of diluted Matrigel $(0.5 \mathrm{mg} / \mathrm{ml}$; BD Biosciences, Franklin Lakes, NJ, USA) for $2 \mathrm{~h}$, and the cells were seeded onto the insert with or without MMPL for $18 \mathrm{~h}$. The membranes to which cells migrated were fixed in $3.7 \%$ paraformaldehyde in PBS, and cells adhering to the upper surface of the membrane were removed with a cotton swab. The invasive cells were stained with $0.5 \%$ crystal violet. After being dried, five random fields of the membrane were observed and counted by averaging the total number of cells at x100 magnification.

Luciferase assay. A luciferase reporter plasmid containing the uPAR $(-682 /+27)$ promoter region (pcDNA3.1-uPAR $(-682 /+27)-$ luc) was constructed with the insertion of a $709 \mathrm{bp}$ polymerase chain reaction (PCR) product (using the specific primers: sense, 5'-GGG GCT AGA TCT GAT TCT CCT GCC TCA GCC TC-3' with $B g l I I$ site and antisense, 5'-CCG GAA TTC GGG TCC CTG CAC GTC TTC TC-3' with EcoRI site) into the BglII and EcoRI sites of the plasmid pcDNA3.1-luc, which contains the luciferase gene. For luciferase assays, the cells were co-transfected with pcDNA3.1-uPAR (-682/+27)-luc 
along with a gWIZ-green fluorescence protein (GFP) plasmid using polyethylenimine (PEI, Polysciences, Inc., Warrington, PA, USA); transfected cells were then divided into 12-well plates $\left(1 \times 10^{5}\right.$ cells/well). After $24 \mathrm{~h}$ of incubation, cells were treated with various concentrations of MMPL for $24 \mathrm{~h}$. Cells were then lysed with passive lysis buffer (Promega, Madison, WI, USA) and promoter activity was assayed according to the manufacturer's instructions. Cell lysates were assayed for GFP expression and the relative luciferase activity was normalized against the levels of GFP expression.

Gelatin zymography. The activity of matrix metalloproteinases (MMP-2 and MMP-9) was assayed by gelatin zymography (24). Briefly, SK-Hep1 cells $\left(3.5 \times 10^{6}\right.$ cells/ well) were seeded in 6-well culture plates and incubated in serum-free medium in the presence of indicated concentrations of MMPL for $24 \mathrm{~h}$, and the cultured media were collected. The samples were mixed with $5 \mathrm{X}$ sample buffer [312.5 mM Tris-Cl ( $\mathrm{pH} 6.8$ ), 5\% sodium dodecyl sulfate (SDS), $50 \%$ glycerol, and $0.05 \%$ bromophenol blue] and separated by $10 \%$ SDS-polyacrylamide gel electrophoresis (PAGE) containing $0.1 \%$ gelatin. The gels were washed with wash buffer [50 mM Tris- $\mathrm{HCl}(\mathrm{pH} 7.5), 0.2 \mathrm{M} \mathrm{NaCl}, 5 \mathrm{mM}$ $\mathrm{CaCl}_{2}, 0.1 \mu \mathrm{M} \mathrm{ZnCl}$, and $2.5 \%$ Triton $\mathrm{X}-100$ ) twice for $30 \mathrm{~min}$ at room temperature (RT) and then incubated in substrate buffer [50 mM Tris- $\mathrm{HCl}(\mathrm{pH} 7.5), 0.2 \mathrm{M} \mathrm{NaCl}, 5 \mathrm{mM} \mathrm{CaCl}{ }_{2}$, $0.1 \mu \mathrm{M} \mathrm{ZnCl}_{2}, 0.016 \% \mathrm{NaN}_{3}$, and $1 \%$ Triton $\left.\mathrm{X}-100\right]$ at $37^{\circ} \mathrm{C}$ for $18 \mathrm{~h}$. The gels were fixed with fixing solution (40\% methanol and $10 \%$ acetic acid) for $30 \mathrm{~min}$ and then stained with staining solution ( $0.25 \%$ Coomassie brilliant blue R-250, $45 \%$ methanol, and $10 \%$ acetic acid) for $1 \mathrm{~h}$, followed by destaining with destaining solution (5\% methanol and $8 \%$ acetic acid). The zymography gels were scanned using an HP Photosmart image scanner (HP Development Co., L.P., Palo Alto, CA, USA). The band intensities were quantified using LabWorks Analysis software (UVP, LLC, Upland, CA, USA).

Telomerase repeat amplification protocol (TRAP) assay. Telomerase activity was measured by a modified TRAP method (25). SK-Hep1 cells $\left(3.5 \times 10^{6}\right.$ cells/well) were seeded in 6-well culture plates and incubated with media containing $1 \%$ FBS in the presence of indicated concentrations of MMPL for $24 \mathrm{~h}$. Cells were lysed with CHAPS lysis buffer [0.5\% CHAPS, 10 mM Tris- $\mathrm{HCl}$ (pH 7.5), 1 mM MgCl $2,1 \mathrm{mM}$ ethylenediaminetetraacetic acid (EDTA), $0.1 \mathrm{mM}$ phenylmethylsulfonyl fluoride (PMSF), $5 \mathrm{mM} \beta$-mercaptoethanol, and $10 \%$ glycerol] on ice for $30 \mathrm{~min}$. Cell lysates were centrifuged at $13,000 \mathrm{xg}$ for $30 \mathrm{~min}$ at $4^{\circ} \mathrm{C}$, and the supernatants were used for the TRAP assays.

For the direct telomerase activity assay with endogenous telomerase, cell lysates were mixed with different concentrations of MMPL for $30 \mathrm{~min}$ on ice before the TRAP assay was performed as previously described (26). Cell extracts $(2 \mu \mathrm{g})$ were mixed with $5 \mu \mathrm{l}$ of $10 \mathrm{X}$ TRAP reaction buffer [200 mM Tris-HCl (pH 8.3), $15 \mathrm{mM} \mathrm{MgCl}_{2}, 630 \mathrm{mM}$ $\mathrm{KCl}, 0.5 \%$ Tween-20 and $10 \mathrm{mM}$ EDTA], $400 \mu \mathrm{g} / \mathrm{ml} \mathrm{BSA}$, $2.5 \mathrm{mM}$ dNTP, $150 \mathrm{ng}$ of TS (telomerase substrate oligonucleotide) primer (5'-AAT CCG TCG AGC AGA GTT-3'), $100 \mathrm{ng}$ of ACX reverse primer [5'-GCG CGG (CTT ACC)3 CTA ACC-3'], $150 \mathrm{ng}$ of NT internal control primer (5'-ATC
GCT TCT CGG CCT TTT-3'), 0.1 pM TSNT (substrate for 36 bp internal standard control) primer (5'-AAT CCG TCG AGC AGA GTT AAA AGG CCG AGA AGC GAT-3'), and $5 \mathrm{U}$ of Taq polymerase (Dynebio Inc., Seoul, Korea). The incubation was performed at $25^{\circ} \mathrm{C}$ for $30 \mathrm{~min}$. PCR was then performed $\left(95^{\circ} \mathrm{C}\right.$ for $5 \mathrm{~min}$ followed by 20 cycles at $95^{\circ} \mathrm{C}$ for $30 \mathrm{sec}, 52^{\circ} \mathrm{C}$ for $30 \mathrm{sec}$ and $72^{\circ} \mathrm{C}$ for $\left.30 \mathrm{sec}\right)$. The reaction mixture (total volume of $50 \mu \mathrm{l}$ ) mixed with $5 \mu \mathrm{l}$ of loading solution $(0.25 \%$ bromophenol blue, $50 \%$ glycerol, and $50 \mathrm{mM}$ EDTA) was separated on a $12 \%$ non-denaturing PAGE gel for $45 \mathrm{~min}$ at $200 \mathrm{~V}$. Gels were stained with ethidium bromide staining solution for $3 \mathrm{~min}$ and visualized with a UV illuminator.

For the expression of human telomerase catalytic unit (hTERT) and human telomerase RNA (hTR), reverse-transcription polymerase chain reaction (RT-PCR) was carried out. Total RNA was extracted using Accuzol solution (Bioneer, Daejeon, Korea) and $1 \mu \mathrm{g}$ of total RNA was used for cDNA synthesis. Relative mRNA expression levels were normalized to the expression levels of glyceraldehyde 3-phosphate dehydrogenase (GAPDH). The PCR products were separated on a $2 \%$ agarose gel and visualized with a UV illuminator. PCR was performed on the cDNA using the following primers; hTERT, 5'-CGG AAG AGT GTC TGG AGC AA-3' (forward) and 5'-GGA TGA AGC GGA GTC TGG A-3' (reverse) (27); $h T R, 5^{\prime}$-ACC CTA ACT GAG AAG GGC GT-3' (forward) and 5'-GCC AGC AGC TGA CAT TTT TT-3' (reverse) (28); GAPDH, 5'-GTC TTC ACC ACC ATG GAG AAG G-3' (forward) and 5'-CCT GCT TCA CCA CCT TCT TGA T-3' (reverse).

Immunoblotting analysis. SK-Hep1 cells were seeded with $10 \%$ FBS-containing media. When cells reached $80 \%$ confluence, they were treated with the indicated concentrations of MMPL for $24 \mathrm{~h}$. Total proteins were extracted in lysis buffer containing $20 \mathrm{mM}$ Tris- $\mathrm{HCl}$ (pH 7.5), $150 \mathrm{mM} \mathrm{NaCl}, 1 \mathrm{mM}$ EDTA, $0.5 \%$ Triton X-100, 0.5\% IGEPAL, $10 \%$ glycerol, $1 \mathrm{mM}$ dithiothreitol, and $1 \mathrm{mM}$ PMSF. Concentrations of soluble cell lysates were measured using Bradford protein assay kit (Bio-Rad, Hercules, CA, USA) and the samples were boiled at $100^{\circ} \mathrm{C}$ for $5 \mathrm{~min}$. Next, $20-40 \mu \mathrm{g}$ of cell lysates were separated on a $10 \%$ polyacrylamide gel and transferred onto a nitrocellulose membrane as described (29). The membrane was blocked in 5\% non-fat dry milk for $1 \mathrm{~h}$ at RT and incubated with appropriate antibodies with 5\% BSA or $5 \%$ non-fat dry milk, followed by incubation with a secondary antibody conjugated to horseradish peroxidase. The immunoreactive bands were visualized using an ECL system (Pierce, Rockford, IL, USA) and a cooled chargedevice camera system (AE-9150; ATTO Technology, Tokyo, Japan). The band intensities were quantified using LabWorks Analysis software.

Statistical analysis. All data represent three independent experiments and are expressed as means \pm standard error of the mean (SEM). Statistical analyses were performed with a one-way ANOVA of Dunnett's Multiple Comparison method using Prism 3.0 (GraphPad Software, San Diego, CA, USA) and $\mathrm{p}<0.05, \mathrm{p}<0.01$, and $\mathrm{p}<0.001$ were considered to indicate statistically significant. 
A

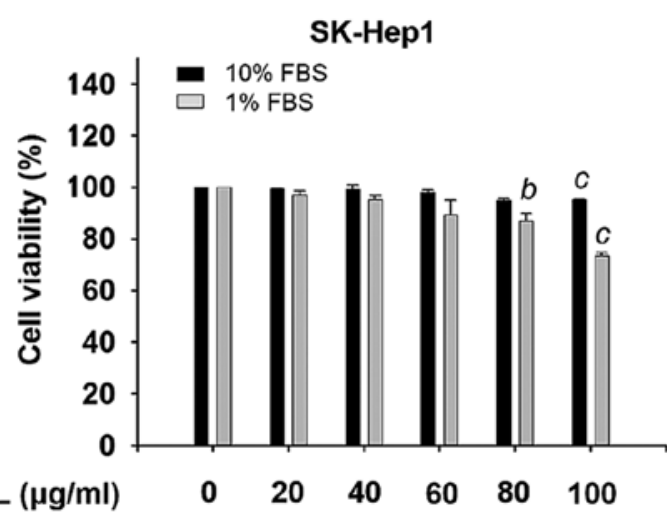

B

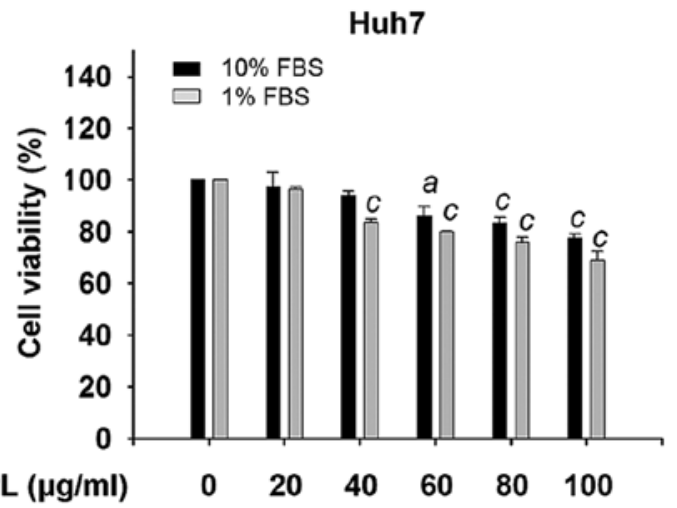

Figure 1. Effects of MMPL on cell viability. SK-Hep1 and Huh7 cells were treated with MMPL (0, 20, 40, 60, 80 and 100 $\mu \mathrm{g} / \mathrm{ml})$ for $24 \mathrm{~h}$ in cell culture media containing $1 \%$ or $10 \%$ FBS. Cell viability was determined by an assay using EZ-Cytox solution. Data shown are representative of three experiments and expressed as the means $\pm \operatorname{SEM}(\mathrm{n}=3) .{ }^{\mathrm{a}} \mathrm{p}<0.05,{ }^{\mathrm{b}} \mathrm{p}<0.01$, and ${ }^{\mathrm{c}} \mathrm{p}<0.001$ relative to the MMPL-untreated control group.

\section{Results}

Effects of MMPL on cell viability. To investigate the cytotoxic effect of MMPL on hepatoma cells, SK-Hep1 and Huh7 cells were incubated with various concentrations of MMPL $(0,20$, 40,60 and $100 \mu \mathrm{g} / \mathrm{ml}$ ) for $24 \mathrm{~h}$ in cell culture media with $1 \%$ or $10 \%$ FBS. Cell viability was examined using EZ-Cytox solution and the effect of MMPL on cell viability is expressed as a percentage of the control (Fig. 1). For SK-Hep1 cells, the results showed little or no effect on cell viability in cell culture media with $1 \%$ and $10 \%$ FBS and $\leq 80 \mu \mathrm{g} / \mathrm{ml}$ of MMPL (Fig. 1A). For Huh7 cells, MMPL slightly inhibited cell viability in a dose-dependent manner but it did not induce cytotoxicity until the concentration was $>40 \mu \mathrm{g} / \mathrm{ml}$ (Fig. 1B). Therefore, MMPL concentrations $\leq 80 \mu \mathrm{g} / \mathrm{ml}$ in SK-Hep1 cells and $40 \mu \mathrm{g} / \mathrm{ml}$ in Huh7 cells were used throughout this study to eliminate the effect of MMPL-induced cytotoxicity on cell migration and invasion.

Inhibitory effects of MMPL on cell migration and invasion. Tumor progression requires cells to migrate and induce degradation of the extracellular matrix (ECM) or basement membrane (BM) for efficient cell invasion (30). Wound healing assays were performed to evaluate the effect of MMPL on cell migration. Cells were treated with various concentrations of MMPL and the cell confluence within the wound regions was measured using a Real-Time Cell History Recorder. The results showed that MMPL significantly suppressed wound closure in a dose- and time-dependent manner (Fig. 2A and B). When SK-Hep1 cells were treated with MMPL for $24 \mathrm{~h}$, the percentage of wound recovery was decreased from $57.2 \pm 4.6 \%(0 \mu \mathrm{g} / \mathrm{ml})$ to $30.9 \pm 1.8 \%$ (60 $\mu \mathrm{g} / \mathrm{ml})$ (Fig. 2A). For Huh7 cells, MMPL also inhibited wound recovery in a dose-dependent manner from $40.3 \pm 2.3 \%$ $(0 \mu \mathrm{g} / \mathrm{ml})$ to $15.4 \pm 1.9 \%$ (40 $\mu \mathrm{g} / \mathrm{ml})$ (Fig. 2B).

To further investigate the effect of MMPL on the motility of SK-Hep1 cells, migration and invasion assays were performed using a Transwell chamber. As shown in Fig. 2C, the result indicated that MMPL inhibited the migration of SK-Hep1 cells in a dose-dependent manner compared to the control group; the motility decreased by $54.8 \pm 9.5 \%$ after treatment with $60 \mu \mathrm{g} / \mathrm{ml}$ MMPL.
The BM and ECM environments, composed of collagen, fibronectin, and laminin, are the first barriers that cancer cells must overcome for invasion (31). Thus, invasion assays were conducted using a Matrigel-coated Transwell chamber to determine whether MMPL reduces the invasive potency of SK-Hep1 cells. MMPL significantly inhibited the invasion of SK-Hep1 cells in a dose-dependent manner (Fig. 2C). Results showed that cell invasion decreased by $54.7 \pm 5.1 \%$ after treatment with $60 \mu \mathrm{g} / \mathrm{ml}$ MMPL. Taken together, these results suggest that MMPL has an inhibitory effect on the metastatic properties of hepatoma cell lines.

Inhibitory effects of MMPL on MMP-2 and MMP-9 activity. In cancer progression, MMPs are essential for the facilitation of cellular metastasis (32). Through the urokinase-type plasminogen activator (UPA)-uPAR signaling pathway, the expression and activation of MMPs are promoted, which enhances ECM degradation (33). Among MMPs, MMP-2 and MMP-9 are highly activated type IV collagenases which play critical roles in tumor invasion and metastasis by facilitating enzymatic digestion of the BM (34-36). Thus, the enzymatic activity of MMP-2 and MMP-9 was measured using gelatin zymography after SK-Hep1 cells were treated with various concentrations of MMPL $(0,20,40$ and $60 \mu \mathrm{g} / \mathrm{ml})$ for $24 \mathrm{~h}$. As shown in Fig. 3A, the constitutive secretion of low levels of MMP-2 and high levels of MMP-9 by untreated SK-Hep1 cells was observed. When cells were treated with MMPL, the activity of MMP-2 and MMP-9 was significantly inhibited in a dose-dependent manner. These results indicate that the inhibitory effect of MMPL on cell migration and invasion might be due to the downregulation of MMP-2 and MMP-9 activity.

Inhibitory effects of MMPL on telomerase activity. Recently, telomerase has been considered critical for carcinogenesis $(9,37)$. To investigate whether MMPL inhibits telomerase activity, SK-Hep1 cells were treated with MMPL. Subsequently, the TRAP assay was performed using cell lysates to determine telomerase activity. As shown in Fig. 3B, telomerase activity was suppressed by MMPL in a dose-dependent manner. 5-FU, which was used as a positive control (38), also inhibited telomerase activity. 

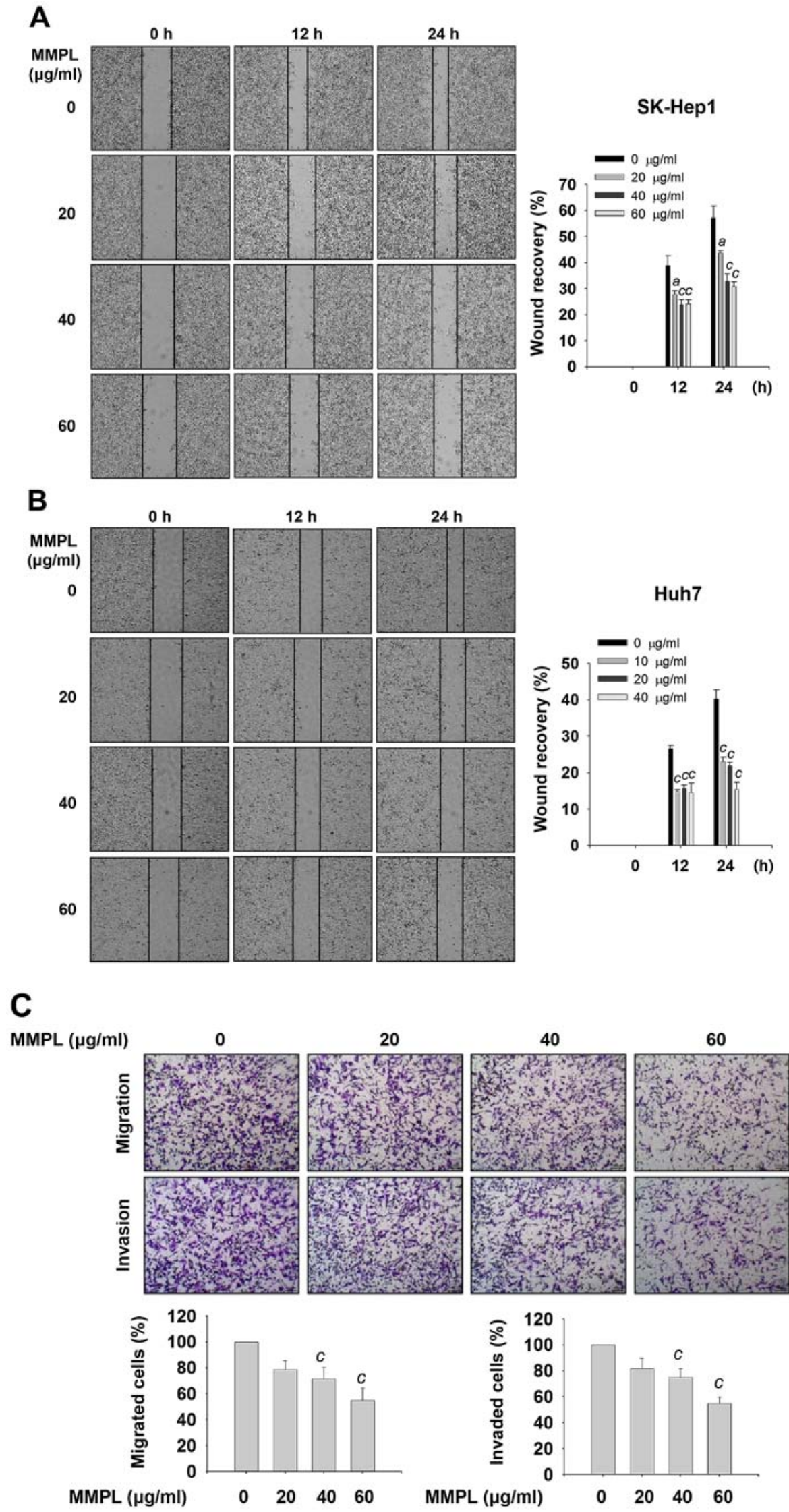

Figure 2. Effects of MMPL on cell migration and invasion. After SK-Hep1 and Huh7 cells were scratched with a scratcher tip, (A) SK-Hep1 cells with MMPL $(0,20,40$ and $60 \mu \mathrm{g} / \mathrm{ml})$ and (B) Huh7 cells with MMPL $(0,10,20$ and $40 \mu \mathrm{g} / \mathrm{ml})$ were incubated in cell culture media containing $1 \%$ FBS for $24 \mathrm{~h}$. Cell motility was quantified by measuring the percent of wound recovery area compared to the zero time-point. (C) SK-Hepl cells with MMPL $(0,20,40$ and $60 \mu \mathrm{g} / \mathrm{ml})$ in media containing $1 \%$ FBS were seeded into upper chamber wells that were coated with or without the Matrigel. The lower chambers were filled with media containing 10\% FBS. After incubation for $18 \mathrm{~h}$, cells that penetrated the lower surface of the filter were fixed and stained with crystal violet. Quantification of migrated and invaded cells was performed by counting cells in five random fields. Data shown are a representative of three experiments and expressed as the means $\pm \operatorname{SEM}(n=3) .{ }^{a} p<0.05$ and ${ }^{c} p<0.001$ relative to the MMPL-untreated control group. 
A

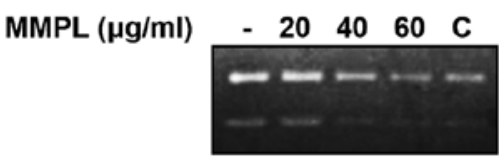

MMP-9

MMP-2

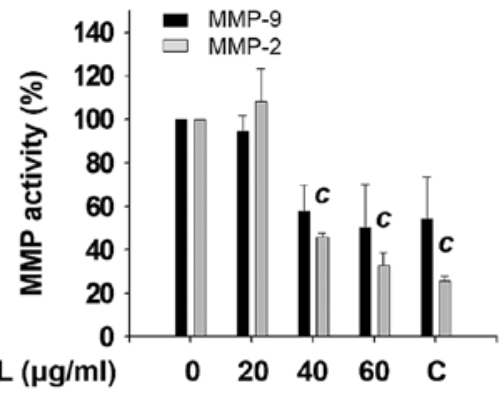

MMPL $(\mu \mathrm{g} / \mathrm{ml})$

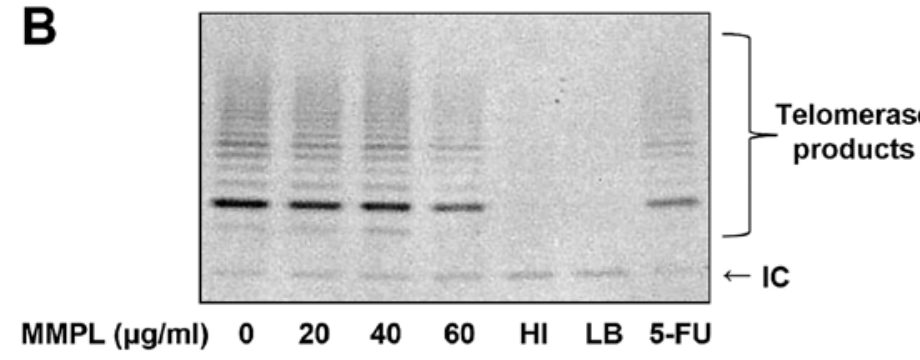

$\begin{array}{llllllll}\text { MMPL }(\mu \mathrm{g} / \mathrm{ml}) & 0 & 20 & 40 & 60 & \text { HI } & \text { LB } & 5-\mathrm{FU}\end{array}$

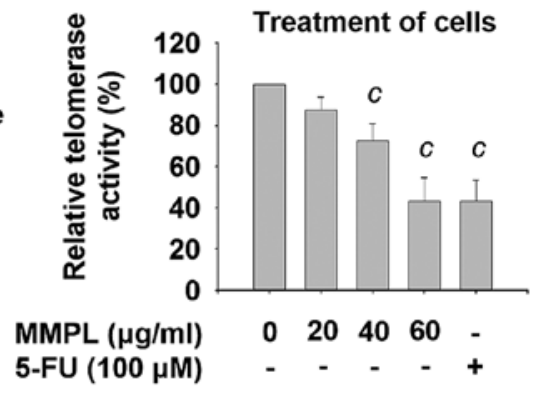

\& Treatment of cell lysates

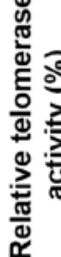

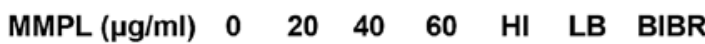

Telomerase products

0

MMPL $(\mu \mathrm{g} / \mathrm{ml})$ BIBR1532 (5 $\mu \mathrm{M})$
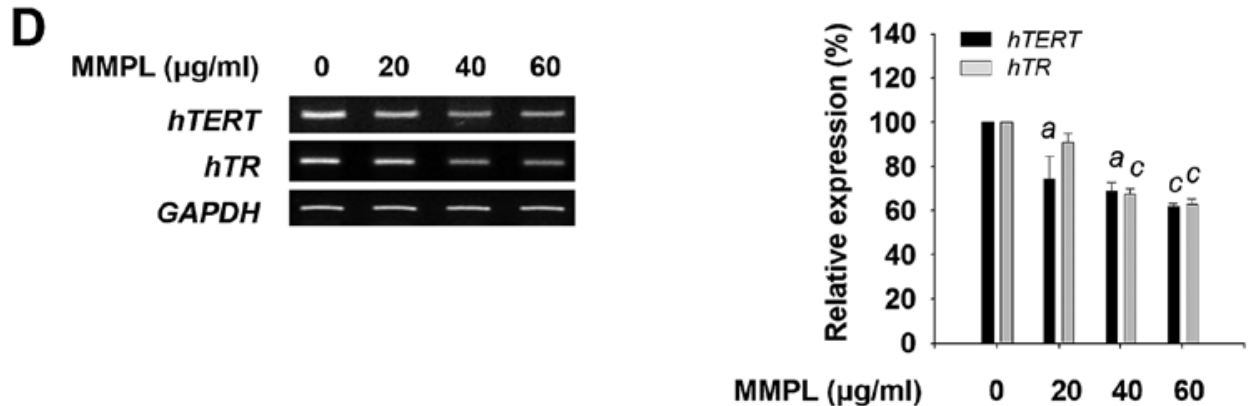

Figure 3. Effects of MMPL on MMP-2, MMP-9, and telomerase activity. (A) SK-Hep1 cells were treated with MMPL (0, 20, 40 and $60 \mu \mathrm{g} / \mathrm{ml})$ in serum-free media for $24 \mathrm{~h}$. The cultured media were collected and the activity of secreted MMP-2 and MMP-9 was determined using gelatin zymography as described in Materials and methods. Emodin $(10 \mu \mathrm{M})$ was used as a positive control (C). (B) SK-Hep1 cells were treated with MMPL $(0,20,40 \mathrm{and} 60 \mu \mathrm{g} / \mathrm{ml})$ in media containing $1 \%$ FBS for $24 \mathrm{~h}$. Telomerase activity was determined by performing a TRAP assay with cell lysates. (C) To detect the direct effect of MMPL on telomerase activity, cell lysates were incubated with indicated concentrations of MMPL for $3 \mathrm{~h}$ and then the TRAP assay was performed in a cell-free condition. (D) SK-Hepl cells were treated with MMPL $(0,20,40$ and $60 \mu \mathrm{g} / \mathrm{ml})$ in media containing $1 \%$ FBS for 24 h. RT-PCR was carried out to measure the expression of $h T E R T$ and $h T R$. Expression of GAPDH was used as an internal control. Data shown are a representative of three experiments and expressed as the means $\pm \operatorname{SEM}(n=3) .{ }^{\mathrm{a}} \mathrm{p}<0.05,{ }^{\mathrm{b}} \mathrm{p}<0.01$, and ${ }^{\mathrm{c}} \mathrm{p}<0.001$ relative to the MMPL-untreated control group. IC, internal control; HI, heat inactivation; LB, lysis buffer; 5-FU, 5-fuorouracil.

To determine whether MMPL can directly suppress the enzymatic activity of telomerase, a telomerase activity assay was carried out after cell lysates were treated with MMPL. The results presented in Fig. 3C show a significant decrease in telomerase activity by MMPL compared with the known telomerase inhibitor BIBR1532 (39).

Telomerase has two core components, hTERT and hTR (40). When SK-Hep1 cells were treated with MMPL, the mRNA levels of $h T E R T$ and $h T R$ were also inhibited in a dose-dependent manner (Fig. 3D). Collectively, MMPL can directly inhibit the enzymatic activity of telomerase and indirectly diminish its activity through the downregulation of $h T E R T$ and $h T R$ expression, suggesting telomerase is a potential target of MMPL in hepatoma cells.

Inhibitory effects of MMPL on UPAR, STAT3, and ERK signaling pathways. Since increased expression of UPAR has been reported in several types of cancer, uPAR is an attractive 


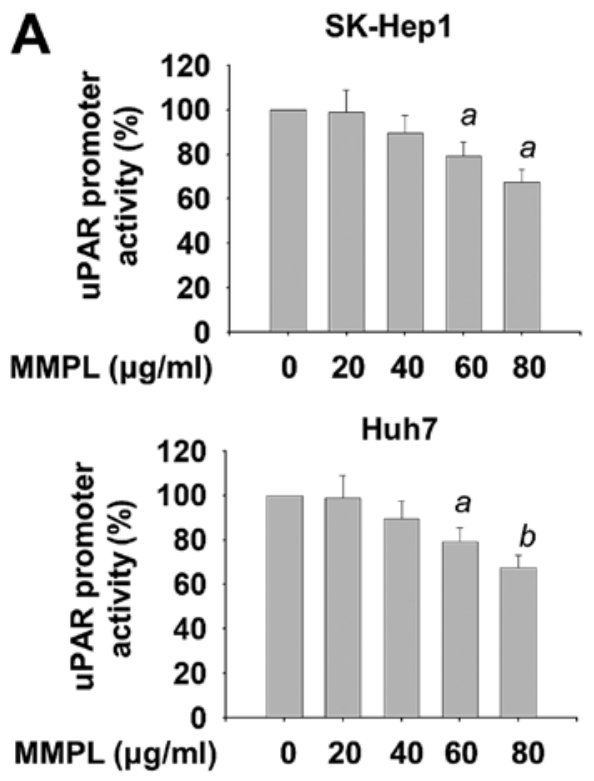

B

MMPL $(\mu \mathrm{g} / \mathrm{ml}) \quad 0 \quad 20 \quad 40$

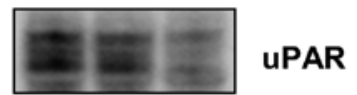

Fold: $\begin{array}{lll}1.0 & 0.8 & 0.4\end{array}$

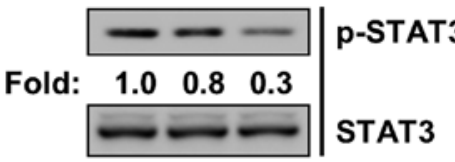

Fold: $\begin{array}{lll}1.0 & 0.7 & 0.4\end{array}$ p-ERK

\section{C}

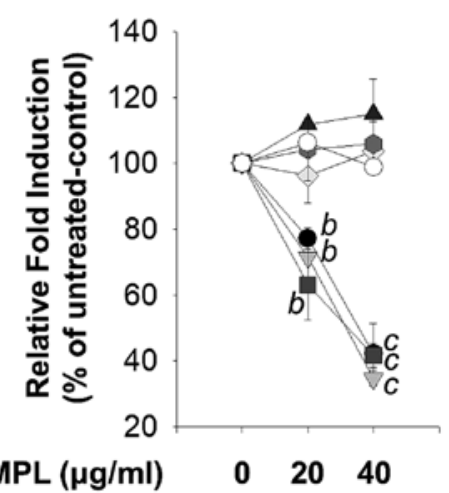

- UPAR

$\nabla$ p-STAT3

a $\mathrm{p}-\mathrm{ERK}$

$\diamond \mathrm{p}-\mathrm{Akt}$

A $\mathrm{p}-\mathrm{JNK}$

- p-p38

- IאB
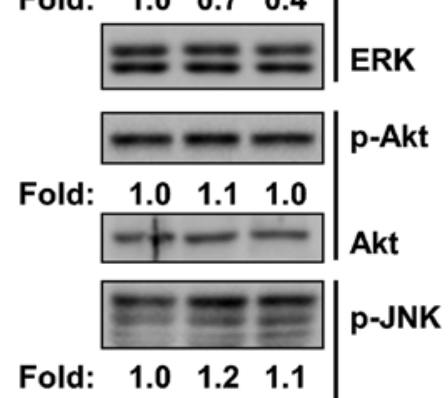

Fold: $\begin{array}{lll}1.0 & 1.2 & 1.1\end{array}$
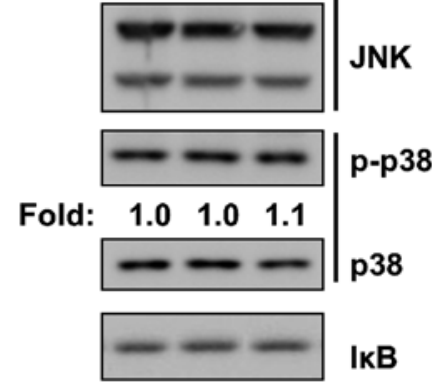

Fold: $\begin{array}{lll}1.0 & 1.1 & 1.0\end{array}$

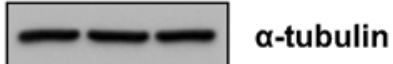

Figure 4. Effects of MMPL on uPAR, ERK, and STAT3 signaling pathway. (A) Following transfection with pcDNA3.1-uPAR (-682/+27)-luc and gWIZ-GFP as an internal control, SK-Hep1 and Huh7 cells were treated with MMPL $(0,20,40,60$ and $80 \mu \mathrm{g} / \mathrm{ml})$ in media containing $10 \%$ FBS for $24 \mathrm{~h}$. Total cell lysates were prepared using passive lysis buffer and UPAR luciferase activity was measured using a microplate reader after reacting the lysates with luciferin as a substrate. (B) SK-Hep1 cells were treated with MMPL (0, 20 and $40 \mu \mathrm{g} / \mathrm{ml})$ in media containing $1 \%$ FBS for 24 h. Total cell lysates were harvested and separated by SDS-PAGE as described in Materials and methods. The expression levels of uPAR, p-STAT3 (Tyr705), STAT3, p-ERK (Thr202/Tyr204), ERK, p-Akt (Ser473), Akt, p-JNK (Thr183/Tyr185), JNK, p-p38 (Thr180/Tyr182), p38, and IkB were detected by specific antibodies. $\alpha$-tubulin was used as a loading control. (C) The graph illustrates the quantitative analysis data of immunoblot band intensities shown in (B). Data shown are normalized to $\alpha$-tubulin expression and expressed as the means $\pm \operatorname{SEM}(\mathrm{n}=3) .{ }^{\mathrm{a}} \mathrm{p}<0.05,{ }^{\mathrm{b}} \mathrm{p}<0.01$, and ${ }^{\mathrm{c}} \mathrm{p}<0.001$ relativeto the MMPL-untreated control group.

therapeutic target for the treatment of cancer metastasis (41). uPAR regulates ECM proteolysis by binding to UPA and promotes cell migration, invasion, and metastasis at cellular surfaces (42). Since MMPL significantly blocked cell motility and the activity of MMPs, reporter assays using a luciferase reporter plasmid containing the UPAR (-682/+27) promoter region were carried out in SK-Hep1 and Huh7 cells. Cells were transfected with pcDNA3.1-uPAR (-682/+27)-luc and then treated with indicated concentrations of MMPL $(0,20,40,60$ and $80 \mu \mathrm{g} / \mathrm{ml}$ ) for $24 \mathrm{~h}$. As shown in Fig. 4A, uPAR promoter activity was suppressed by MMPL in a dose-dependent manner in SK-Hep1 and Huh7 cells. Immunoblotting analysis with cell lysates obtained from MMPL-treated SK-Hep1 cells was performed to further investigate the effect of MMPL on the level of uPAR protein. As shown in Fig. 4B and C, uPAR protein expression decreased in a dose-dependent manner.
Taken together, these results suggest that MMPL can attenuate transactivation of uPAR in hepatoma cells.

Many signaling pathways, such as uPA/uPAR, Janus kinase (JAK)/STAT, phosphatidylinositol-3-kinase (PI3K)/Akt, mitogen-activated protein kinase (MAPK), and nuclear factor kappa-B $(\mathrm{NF}-\kappa \mathrm{B})$, are involved in human cancer progression (43-46). To examine how MMPL suppresses the metastatic ability of hepatoma cells by targeting signaling pathways, the expression levels of phosphorylated STAT3, MAPKs, Akt, and inhibitor of $\kappa \mathrm{B} \alpha(\mathrm{I} \kappa \mathrm{B} \alpha)$ were measured using immunoblotting analysis after incubating SK-Hep1 cells with indicated concentrations of MMPL $(0,20$ and $40 \mu \mathrm{g} / \mathrm{ml})$ for $24 \mathrm{~h}$. As shown in Fig. 4B and C, phosphorylation levels of STAT3 at Tyr705 were dose-dependently suppressed by MMPL in SK-Hep1 cells without changing the total protein levels of STAT3. In addition, among three conventional MAPKs (ERK, JNK, and 
p38), MMPL inhibited the phosphorylation levels of ERK at Thr202/Tyr204 in a dose-dependent manner without changing the total protein levels of ERK. To examine the regulation of PI3K/Akt, one of the most frequently altered pathways in human cancer (47), we investigated the change in phosphorylation levels of Akt at Ser473 by MMPL. However, no significant change was found. Since NF- $\mathrm{KB}$ activity is involved in the regulation of UPAR expression (48) and because its transcriptional activity is regulated by the phosphorylation dependent-proteasomal degradation of ІкB (49), the expression levels of $\mathrm{I} \kappa \mathrm{B} \alpha$ protein were also measured. We found that MMPL did not affect the levels of IкB $\alpha$. Taken together, these results suggest that the anticancer effects of MMPL in hepatoma cells are regulated through inhibition of the STAT3 and ERK pathways.

\section{Discussion}

HCC, a primary malignancy of the liver, is now the third leading cause of cancer death worldwide (50). There has been increasing interest in characterizing the molecular mechanisms of HCC in order to develop novel therapeutic approaches (51). In this study, the suppressive action of MMPL as a potential anticancer agent was explored in hepatoma cells.

Recently, the development and design of drugs affecting multiple targets or pathways have emerged for cancer treatment (52). Natural products such as curcumin, berberine, and baicalein are rich reservoirs due to their structural and chemical diversity; therefore, the discovery of drug candidates by screening natural products is considered to be an effective strategy for the development of new anticancer drugs $(53,54)$. Natural products-derived chemotherapeutic drugs have shown cancer chemopreventive activity whereas many of common chemotherapeutic drugs such as doxorubicin, 5-FU, bleomycin, and cyclophosphamide cause toxic side-effects as a results of chemotherapeutic treatments (55-59). Therefore, the discovery of drug candidates by screening natural products is considered to be an effective strategy for the development of new anticancer drugs. This study found that MMPL inhibits cell migration and invasion by inhibiting MMPs and uPAR via the regulation of the ERK and STAT3 pathways; MMPL may therefore be a good candidate to improve HCC treatment.

In addition, the toxicity of many anticancer agents on normal tissues and organs often limits their use. Since side effects occur with almost all anticancer agents (60), novel anticancer agents must overcome this obstacle. In previous studies, normal monkey kidney Vero cells were not susceptible to the cytotoxicity of the methanol extract of Myrmecodia platytyrea Becc. with an $\mathrm{IC}_{50}$ value of $0.76 \mathrm{mg} / \mathrm{ml}$, and oral administration of the extract was not harmful to mice. However, the extract was toxic to human hepatoma HepG2 cells with an $\mathrm{IC}_{50}$ value of $0.07 \mathrm{mg} / \mathrm{ml}$, suggesting Myrmecodia platytyrea Becc. has the potential to treat liver cancer without affecting normal cells $(23,61)$.

Proteolytic enzymes, including metallo-, serine-, aspartyl-, and cysteine proteases, play critical roles in cancer progression and metastasis (62). uPA, a serine protease, binds to UPAR with high affinity and facilitates the conversion of plasminogen to plasmin; plasmin then degrades the ECM and activates other proteases, such as MMPs, leading to tissue remodeling for cancer invasion and progression (62). It has been shown that high expression levels of MMPs and uPA correlate with aggressive behavior of HCC growth and metastasis $(35,63)$. Therefore, suppressing the expression or activity of these proteases has been considered a valuable target against HCC. In this study, MMPL clearly inhibited the migration and invasion of SK-Hep1 cells (Fig. 2). Furthermore, MMPL suppressed protein expression levels of UPAR as well as the enzymatic activity of MMP-2 and MMP-9 in a dose-dependent manner (Figs. 3 and 4). This indicated that MMPL inhibits the metastatic activity of hepatoma cells through the downregulation of uPAR expression, thereby contributing to the decrease in MMP activity. Further studies are needed to confirm whether the reduction of MMP-2 and MMP-9 activity is due to their decreased protein expression.

Cancer metastasis is regulated by complex molecular mechanisms. Recent studies have demonstrated that PI3K/Akt and MAPKs, such as ERK, JNK, and p38, are involved in regulating the expression of MMPs, uPA, as well as uPAR. Furthermore, the STAT3 signaling pathway plays a critical role in the regulation of MMPs and UPAR. These studies imply that the inhibition of these pathways represents a potential target for new anti-metastasis therapies. In the present study, MMPL inhibited the phosphorylation levels of ERK at Thr202/Tyr204 and STAT3 at Tyr705 in a dose-dependent manner, but it did not inhibit phosphorylation of JNK at Thr183/Tyr185 or p38 at Thr180/Tyr182 (Fig. 4B). Collectively, these results suggest that the anti-metastatic activity of MMPL is mediated through the inhibition of the ERK and STAT3 pathways.

In most normal cells, telomerase activity is minimal after embryonic differentiation except in germ cells, stimulated lymphocytes, and stem cells $(8,64,65)$. Therefore, the length of telomeres decreases with age and normal cells have a limited capacity to divide. However, upregulated telomerase activity has been detected in most cancer cells and contributes to the proliferation of cancer (9). In addition, cancer initiating cells are likely to have short telomeres compared with normal cells, suggesting cancer cells are more susceptible to telomerase inhibition (66). Therefore, telomerase is considered to be a useful target in cancer treatment. Two major components of telomerase, hTERT and hTR, remain suitable targets since their expression and activity are essential for the proper functioning of telomerase $(67,68)$.

Many signaling pathways such as PI3K/Akt/mTOR, MAPK, and JAK/STAT are involved in the regulation of telomerase expression and activity (69-71). It has been reported that ERK1/2 promotes the expression and activation of TERT by stimulating Ets-1, Sp-1, and c-Myc transcriptional factors $(69,72)$. Furthermore, STAT3 activation induces TERT expression by binding to the TERT gene promoter region in various cancer cell lines (71). In the present study, MMPL suppressed telomerase activity and mRNA levels of $h T R$ and hTERT (Fig. 3). In addition, the phosphorylation levels of ERK and STAT3 were inhibited by MMPL (Fig. 4B and C). Taken together, these data suggest that MMPL inhibits telomerase expression and activity by suppressing the ERK and STAT3 pathways. Moreover, MMPL can directly inhibit telomerase activity (Fig. 3C). MMPL might represent a promising new candidate for anti-telomerase therapies. 
Phytochemical investigation of Myrmecodia platytyrea Becc. has been poorly studied. The plant has been reported to possess several compounds such as liquiritigenin, stigmasterol, morindolide, calycosin, 2-(2-methylbutyryl) phloroglucinol glucoside, and an acylated flavanone (22). Liquiritigenin is known to downregulate MMP-2/9 and PI3K/AKT signaling pathway that are involved in cancer metastasis (73). Calycosin also inhibits breast cancer cell growth by regulating p38 and AKT signaling pathways (74). In addition, stigmasterol induces apoptosis in human hepatoma cells (75). Since MMPL exhibits anticancer activity by inhibiting ERK and STAT3 signaling pathways rather than regulating $\mathrm{p} 38$ and AKT activities, further studies are needed to identify the possible active ingredient of the plant for anticancer effects.

Taken together, the results of this study suggest that MMPL has anticancer and anti-metastatic properties in HCC; therefore, MMPL can serve as an effective therapeutic agent for treating human liver cancer.

\section{Acknowledgements}

This study was supported by the National Research Foundation of Korea (NRF) grant funded by the Ministry of Science, ICT and Future Planning (NRF-2015R1A2A2A11001446, and 2015R1A5A1008958) and the Chung-Ang University Excellent Student Scholarship in 2013.

\section{References}

1. Krishnamurthi K: Screening of naturla products for anticancer and antidiabetic properties. Health Administrator XX: 69-75, 2000.

2. Steeg PS: Tumor metastasis: Mechanistic insights and clinical challenges. Nat Med 12: 895-904, 2006.

3. Seyfried TN and Huysentruyt LC: On the origin of cancer metastasis. Crit Rev Oncog 18: 43-73, 2013.

4. Wells A, Grahovac J, Wheeler S, Ma B and Lauffenburger D Targeting tumor cell motility as a strategy against invasion and metastasis. Trends Pharmacol Sci 34: 283-289, 2013.

5. Steeg PS and Theodorescu D: Metastasis: A therapeutic target for cancer. Nat Clin Pract Oncol 5: 206-219, 2008.

6. Agrawal A, Dang S and Gabrani R: Recent patents on antitelomerase cancer therapy. Recent Patents Anticancer Drug Discov 7: 102-117, 2012.

7. Holysz H, Lipinska N, Paszel-Jaworska A and Rubis B Telomerase as a useful target in cancer fighting-the breast cancer case. Tumour Biol 34: 1371-1380, 2013.

8. Kim NW, Piatyszek MA, Prowse KR, Harley CB, West MD, Ho PL, Coviello GM, Wright WE, Weinrich SL and Shay JW: Specific association of human telomerase activity with immortal cells and cancer. Science 266: 2011-2015, 1994.

9. Jafri MA, Ansari SA, Alqahtani MH and Shay JW: Roles of telomeres and telomerase in cancer, and advances in telomerasetargeted therapies. Genome Med 8: 69-88, 2016.

10. Demain AL and Vaishnav P: Natural products for cancer chemotherapy. Microb Biotechnol 4: 687-699, 2011.

11. Norikura T, Kojima-Yuasa A, Shimizu M, Huang X, Xu S, Kametani S, Rho SN, Kennedy DO and Matsui-Yuasa I: Mechanism of growth inhibitory effect of Blumea balsamifera extract in hepatocellular carcinoma. Biosci Biotechnol Biochem 72: 1183-1189, 2008.

12. Machana S, Weerapreeyakul N, Barusrux S, Thumanu K and Tanthanuch W: Synergistic anticancer effect of the extracts from Polyalthia evecta caused apoptosis in human hepatoma (HepG2) cells. Asian Pac J Trop Biomed 2: 589-596, 2012.

13. Huxley CR: The ant-plants Myrmecodia and Hydnophytum (Rubiaceae), and the relationships between their morphology, ant occupants, physiology and ecology. New Phytol 80: 231-268, 1978.
14. Lok AFSL and Tan HTW: Tuberous, epiphytic, rubiaceous myrmecophytes of singapore. Nat Singap 2: 231-236, 2009.

15. Subroto MA and Saputro H: Gempur Penyakit Dengan Sarang Semut. Jakarta Penebar Swadaya, pp11-22, 2006 (In Indonesian).

16. Soeksmanto A, Subroto MA, Wijaya H and Simanjuntak P: Anticancer activity test for extracts of Sarang semut plant (Myrmecodya pendens) to HeLa and MCM-B2 cells. Pak J Biol Sci 13: 148-151, 2010

17. Engida AM, Kasim NS, Tsigie YA, Ismadji S, Huynh LH and $\mathrm{Ju}$ Y-H: Extraction, identification and quantitative HPLC analysis of flavonoids from sarang semut (Myrmecodia pendan). Ind Crops Prod 41: 392-396, 2013.

18. Yuletnawati SE, Meiyanto E and Agustina D: High antitumor activity of ethanolic extracts of Papua's ant nest plant (Myrmecodia tuberosa) on an oral carcinoma (KB) cell line. Int J Sci Res 5: 1619-1623, 2016

19. Sumardi, Hertiani T and Sasmito E: Ant plant (Myrmecodia tuberosa) hypocotyl extract modulates TCD $4^{+}$and $\mathrm{TCD} 8^{+}$cell profile of doxorubicin-induced immune-suppressed sprague dawley rats in vivo. Sci Pharm 81: 1057-1069, 2013.

20. Zhang XY, Li WG, Wu YJ and Gao MT: Amelioration of doxorubicin-induced myocardial oxidative stress and immunosuppression by grape seed proanthocyanidins in tumour-bearing mice. J Pharm Pharmacol 57: 1043-1052, 2005

21. Sultana R, Di DomenicoF, Tseng M, Cai J,Noel T, Chelvarajan RL, Pierce WD, Cini C, Bondada S, St Clair DK, et al: Doxorubicininduced thymus senescence. J Proteome Res 9: 6232-6241, 2010.

22. Mohamad Haris NF, Nik Hasan MK, Wahab IA, Hasan MH, Ponto $\mathrm{T}$ and Adam A: Compounds from the antioxidant active fraction of M. platytyrea. J Sains Kesihatan Malaysia 14: 23-29, 2016.

23. Mizaton HH, Samad MA, Wahab IA, Mohamad Haris NF, Ponto T and Adam A: Toxicological evaluation of Myrmecodia platytyrea. In: 2010 International Conference on Science and Social Research, Kuala Lumpur, 2010. DOI: 10.1109/CSSR.2010.5773797.

24. Lai KC, Huang AC, Hsu SC, Kuo CL, Yang JS, Wu SH and Chung JG: Benzyl isothiocyanate (BITC) inhibits migration and invasion of human colon cancer HT29 cells by inhibiting matrix metalloproteinase-2/-9 and urokinase plasminogen (uPA) through PKC and MAPK signaling pathway. J Agric Food Chem 58: 2935-2942, 2010.

25. Yang L, Suwa T, Wright WE, Shay JW and Hornsby PJ: Telomere shortening and decline in replicative potential as a function of donor age in human adrenocortical cells. Mech Ageing Dev 122: 1685-1694, 2001

26. Pascolo E, Wenz C, Lingner J, Hauel N, Priepke H, Kauffmann I, Garin-Chesa P, Rettig WJ, Damm K and Schnapp A: Mechanism of human telomerase inhibition by BIBR1532, a synthetic, non-nucleosidic drug candidate. J Biol Chem 277: 15566-15572, 2002.

27. Nakamura TM, Morin GB, Chapman KB, Weinrich SL, Andrews WH, Lingner J, Harley CB and Cech TR: Telomerase catalytic subunit homologs from fission yeast and human. Science 277: 955-959, 1997.

28. Heine B, Hummel M, Demel G and Stein H: Demonstration of constant upregulation of the telomerase RNA component in human gastric carcinomas using in situ hybridization. J Pathol 185: 139-144, 1998

29. Le HTT, Cho YC and Cho S: Inhibition of protein tyrosine phosphatase non-receptor type 2 by PTP inhibitor XIX: Its role as a multiphosphatase inhibitor. BMB Rep 50: 329-334, 2017.

30. Friedl $\mathrm{P}$ and Wolf $\mathrm{K}$ : Tumour-cell invasion and migration: Diversity and escape mechanisms. Nat Rev Cancer 3: 362-374, 2003.

31. Gattazzo F, Urciuolo A and Bonaldo P: Extracellular matrix: A dynamic microenvironment for stem cell niche. Biochim Biophys Acta 1840: 2506-2519, 2014.

32. Ellerbroek SM and Stack MS: Membrane associated matrix metalloproteinases in metastasis. BioEssays 21: 940-949, 1999.

33. Danø K, Rømer J, Nielsen BS, Bjørn S, Pyke C, Rygaard J and Lund LR: Cancer invasion and tissue remodeling--cooperation of protease systems and cell types. APMIS 107: 120-127, 1999.

34. Giannelli G, Bergamini C, Marinosci F, Fransvea E, Quaranta M, Lupo L, Schiraldi O and Antonaci S: Clinical role of MMP-2/ TIMP-2 imbalance in hepatocellular carcinoma. Int J Cancer 97: 425-431, 2002.

35. Yeh HC, Lin SM, Chen MF, Pan TL, Wang PW and Yeh CT: Evaluation of serum matrix metalloproteinase (MMP)-9 to MMP-2 ratio as a biomarker in hepatocellular carcinoma. Hepatogastroenterology 57: 98-102, 2010. 
36. Chen R, Cui J, Xu C, Xue T, Guo K, Gao D, Liu Y, Ye S and Ren Z: The significance of MMP-9 over MMP-2 in HCC invasiveness and recurrence of hepatocellular carcinoma after curative resection. Ann Surg Oncol 19 (Suppl 3): S375-S384, 2012.

37. Bernardes de Jesus B and Blasco MA: Telomerase at the intersection of cancer and aging. Trends Genet 29: 513-520, 2013.

38. Padmanabhan P, Otero J, Ray P, Paulmurugan R, Hoffman AR, Gambhir SS, Biswal S and Ulaner GA: Visualization of telomerase reverse transcriptase (hTERT) promoter activity using a trimodality fusion reporter construct. J Nucl Med 47: 270-277, 2006

39. Barma DK, Elayadi A, Falck JR and Corey DR: Inhibition of telomerase by BIBR 1532 and related analogues. Bioorg Med Chem Lett 13: 1333-1336, 2003.

40. Podlevsky JD, Bley CJ, Omana RV, Qi X and Chen JJL: The telomerase database. Nucleic Acids Res 36 (Database): D339-D343, 2008

41. Ulisse S, Baldini E, Sorrenti S and D'Armiento M: The urokinase plasminogen activator system: A target for anti-cancer therapy. Curr Cancer Drug Targets 9: 32-71, 2009.

42. Smith HW and Marshall CJ: Regulation of cell signalling by uPAR. Nat Rev Mol Cell Biol 11: 23-36, 2010.

43. Helbig G, Christopherson KW II, Bhat-Nakshatri P, Kumar S, Kishimoto $\mathrm{H}$, Miller KD, Broxmeyer $\mathrm{HE}$ and Nakshatri $\mathrm{H}$ NF-kappaB promotes breast cancer cell migration and metastasis by inducing the expression of the chemokine receptor CXCR4 J Biol Chem 278: 21631-21638, 2003.

44. Sen B and Johnson FM: Regulation of SRC family kinases in human cancers. J Signal Transduct 2011: 865819, 2011.

45. Noh H, Hong S and Huang S: Role of urokinase receptor in tumor progression and development. Theranostics 3: 487-495, 2013.

46. Steelman LS, Chappell WH, Abrams SL, Kempf RC, Long J, Laidler P, Mijatovic S, Maksimovic-Ivanic D, Stivala F, Mazzarino MC, et al: Roles of the Raf/MEK/ERK and PI3K/ PTEN/Akt/mTOR pathways in controlling growth and sensitivity to therapy-implications for cancer and aging. Aging (Albany NY) 3: 192-222, 2011

47. Fresno Vara JA, Casado E, de Castro J, Cejas P, Belda-Iniesta C and González-Barón M: PI3K/Akt signalling pathway and cancer. Cancer Treat Rev 30: 193-204, 2004.

48. Chang HJ, Kim MH, Baek MK, Park JS, Chung IJ, Shin BA, Ahn BW and Jung YD: Triptolide inhibits tumor promoterinduced uPAR expression via blocking NF-kappaB signaling in human gastric AGS cells. Anticancer Res 27A: 3411-3417, 2007.

49. Oeckinghaus A and Ghosh S: The NF-kappaB family of transcription factors and its regulation. Cold Spring Harb Perspect Biol 1: a000034, 2009.

50. McGlynn KA and London WT: The global epidemiology of hepatocellular carcinoma: Present and future. Clin Liver Dis 15 223-243, vii-x, 2011.

51. Chen C and Wang G: Mechanisms of hepatocellular carcinoma and challenges and opportunities for molecular targeted therapy. World J Hepatol 7: 1964-1970, 2015.

52. Lu JJ, Pan W, Hu YJ and Wang YT: Multi-target drugs: The trend of drug research and development. PLoS One 7: e40262, 2012.

53. Tan W, Lu J, Huang M, Li Y, Chen M, Wu G, Gong J, Zhong Z, $\mathrm{Xu} \mathrm{Z}$, Dang Y, et al: Anti-cancer natural products isolated from chinese medicinal herbs. Chin Med 6: 27, 2011.

54. Srinivas NR: Baicalin, an emerging multi-therapeutic agent: Pharmacodynamics, pharmacokinetics, and considerations from drug development perspectives. Xenobiotica 40: 357-367, 2010.

55. Desai AG, Qazi GN, Ganju RK, El-Tamer M, Singh J, Saxena AK, Bedi YS, Taneja SC and Bhat HK: Medicinal plants and cancer chemoprevention. Curr Drug Metab 9: 581-591, 2008

56. Avilés A, Arévila N, Díaz Maqueo JC, Gómez T, García R and Nambo MJ: Late cardiac toxicity of doxorubicin, epirubicin, and mitoxantrone therapy for Hodgkin's disease in adults. Leuk Lymphoma 1: 275-279, 1993.
57. Macdonald JS: Toxicity of 5-fluorouracil. Oncology (Williston Park) 13 (Suppl 3): 33-34, 1999.

58. Adamson IY: Pulmonary toxicity of bleomycin. Environ Health Perspect 16: 119-126, 1976.

59. Fraiser LH, Kanekal S and Kehrer JP: Cyclophosphamide toxicity. Characterising and avoiding the problem. Drugs 42 : 781-795, 1991.

60. Liang XJ, Chen C, Zhao Y and Wang PC: Circumventing tumor resistance to chemotherapy by nanotechnology. Methods Mol Biol 596: 467-488, 2010.

61. OECD: Acute oral toxicity. Acute oral toxic class method guideline 423 adopted 23.03.1996. In: Eleventh Addendum to the, OECD, guidelines for the testing of chemicals organisation for economical co-operation and development, Paris, June, 2000

62. Skrzydlewska E, Sulkowska M, Koda M and Sulkowski S: Proteolytic-antiproteolytic balance and its regulation in carcinogenesis. World J Gastroenterol 11: 1251-1266, 2005.

63. Sakamoto Y, Mafune K, Mori M, Shiraishi T, Imamura H, Mori M, Takayama T and Makuuchi M: Overexpression of MMP-9 correlates with growth of small hepatocellular carcinoma. Int J Oncol 17: 237-243, 2000.

64. Shay JW and Bacchetti S: A survey of telomerase activity in human cancer. Eur J Cancer 33: 787-791, 1997.

65. Wright WE, Piatyszek MA, Rainey WE, Byrd W and Shay JW: Telomerase activity in human germline and embryonic tissues and cells. Dev Genet 18: 173-179, 1996.

66. Shay JW and Keith WN: Targeting telomerase for cancer therapeutics. Br J Cancer 98: 677-683, 2008.

67. Collado M, Blasco MA and Serrano M: Cellular senescence in cancer and aging. Cell 130: 223-233, 2007.

68. Meyerson M, Counter CM, Eaton EN, Ellisen LW, Steiner P, Caddle SD, Ziaugra L, Beijersbergen RL, Davidoff MJ, Liu Q, et al: hEST2, the putative human telomerase catalytic subunit gene, is up-regulated in tumor cells and during immortalization. Cell 90: 785-795, 1997.

69. Maida Y, Kyo S, Kanaya T, Wang Z, Yatabe N, Tanaka M, Nakamura M, Ohmichi M, Gotoh N, Murakami S, et al: Direct activation of telomerase by EGF through Ets-mediated transactivation of TERT via MAP kinase signaling pathway. Oncogene 21: 4071-4079, 2002.

70. Kawauchi K, Ogasawara T, Yasuyama M, Otsuka K and Yamada O: Regulation and importance of the PI3K/Akt/mTOR signaling pathway in hematologic malignancies. Anticancer Agents Med Chem 9: 1024-1038, 2009.

71. Konnikova L, Simeone MC, Kruger MM, Kotecki M and Cochran BH: Signal transducer and activator of transcription 3 (STAT3) regulates human telomerase reverse transcriptase (hTERT) expression in human cancer and primary cells. Cancer Res 65: 6516-6520, 2005.

72. Bermudez Y, Yang H, Cheng JQ and Kruk PA: Pyk2/ERK 1/2 mediate Sp1- and c-Myc-dependent induction of telomerase activity by epidermal growth factor. Growth Factors 26: 1-11, 2008.

73. Shi H, Wu Y, Wang Y, Zhou M, Yan S, Chen Z, Gu D and Cai Y: Liquiritigenin potentiates the inhibitory effects of cisplatin on invasion and metastasis via downregulation MMP-2/9 and PI3 K/AKT signaling pathway in B16F10 melanoma cells and mice model. Nutr Cancer 67: 761-770, 2015.

74. Chen J, Hou R, Zhang X, Ye Y, Wang Y and Tian J: Calycosin suppresses breast cancer cell growth via ER $\beta$-dependent regulation of IGF-1R, p38 MAPK and PI3K/Akt pathways. PLoS One 9: e91245, 2014.

75. Kim YS, Li XF, Kang KH, Ryu B and Kim SK: Stigmasterol isolated from marine microalgae Navicula incerta induces apoptosis in human hepatoma HepG2 cells. BMB Rep 47: 433-438, 2014 